\title{
Millennial in Facing Society 5.0: Expectations and Anxiety of Millennial Generation towards Society 5.0
}

\author{
Sampoerno $^{1}$, Seto Herwandito ${ }^{2}$ \\ Faculty of Social Science and Communication, Satya Wacana Christian University, \\ Indonesia $^{1,2}$ \\ \{sam_management@yahoo.com ${ }^{1}$,sherwandito@gmail.com²
}

\begin{abstract}
The presence of robots or Artificial Intelligence (A.I) become real in World Economic Forum (WEF) meeting on January 23, 2019, in Davos, Switzerland. Japan became the country carrying Society 5.0. A human-centered society that balances economic progress by solving social problems through a system that profoundly integrates virtual space and physical space. Millennials, or Generation Y, known as multitasking and nimble, are interesting to study. However, what if the job or business was taken over by A.I? How to guarantee that millennial is the leading much player in terms of work, not AI or ICT? This research aims to find out about the expectations and anxieties of the millennial generation towards society 5.0. To gather data, this research using focus group discussion and in-depth interviews. Three groups from 3 different universities in Salatiga-Central Java became participants. Total participants are 14 students from millennial generations. The results are that human or individual traits tend to be mechanical or mechanistic because everything is organized, accurate, and completely autonomous (automatic). Anxiety will only occur or experienced by a group/people that are not ready with the presence of Society 5.0.
\end{abstract}

Keywords: Adaptive; Anxiety; Expectations; Millennial Generation; Society 5.0

\section{Introduction}

In 1969 the world was shocked by the presence of the internet, which was initially a computer network created by a United States Defense Agency (ARPA). The internet has emerged and has changed the world to become all-digital, where we used to live in the era of "printing" now we live in the digital era. The above descriptions are a feature of Industry 4.0, where the concept of factories and machines tied with wireless sensor connectivity or wireless, connected to a system that can visualize all production lines, control, and make their own decisions. Several countries are competing to realize this industry 4.0 [1], such as European countries, Asia, China, North America and Japan with "Society 5.0".

Today our world is filled with globalization, the internet, and artificial intelligence. The impact of this era is the decline of natural resources, global warming, growing economic disparity, and terrorism. Therefore in the World Economic Forum (WEF) on January 23, 2019, in Davos, Switzerland, the State of Japan proposed a Society 5.0 [2], [3]. At a glance, a video 
about society 5.0 [3], [4] made by Japan, provides a very advanced picture of life. However, it should be re-thinking on some points. As we know in future people who become "residents" of society 5.0 is the generation below us, one of them is millennial generation [5]. The problem is that when industry 4.0 grows with AI [1] and robots, it will also take human (millennial) jobs. The fundamental question is, what if those jobs are taken over by AI and robots? What are the expectation and anxiety of millennial generation in the presence of Society 5.0? This paper wants to see the expectation and anxiety of millennial generation regarding society 5.0. The purposes are to find out the expectation, anxiety, and strategies from the viewpoint of the millennial generation in the presence of society 5.0 .

\subsection{Society 5.0}

The concept of industry 4.0 emphasizes more on technological change, industrial digitalization, which is centered on computers and connected using the internet and controlled by software [6]. This form of technology will lead to transformation and ultimately to changes in how people work in the future, where work becomes more straightforward and more accessible [7]. The Japanese government is introducing the concept of Society 5.0 in the 5 th Science and Technology Basic Plan by the Science, Technology, and Innovation Council. Society 5.0 is an impact or development of Industry 4.0, where changes occur in its technology, but the Japanese state sees Society 5.0 as an answer to problems produced by Industry 4.0 [2], such as international competition, industrial infrastructure that demands renovation, natural disasters, terrorism, problems the environment and the scarcity of natural resources [8], [9].

\subsection{The Presence of Robot and Ai}

Society 5.0 is a super-smart society that is the answer to the problems posed by Industry 4.0, where sustainable societies have diverse values linked through the Cyber-Physical (CPS) system, so individuals from different generations will be able to live safely and comfortably [4], [10]. The presence of robots and $\mathrm{Ai}$ is undeniable, and there are five specific areas, namely: (1) Extension of healthy lifespan, (2) Mobility revolution, (3) Next-Generation supply chain, (4) Pleasant infrastructure and towns and (5) FinTech [4], [11].

In the Extension of a healthy lifespan, AI and robots will monitor their health using a smartphone or device. The mobility revolution will involve many technological developments in the field of autonomous cars and drones. For the next-generation supply chain, it will reduce production efficiency by facilitating, connecting, and utilizing data from various fields. In civil infrastructure and towns, Ai, IoT, and robots introduce us to smart living. Finally, FinTech proposes smart contracts by bringing new business opportunities by streamlining business processes and sharing information among industries by combining EDI services with Open API and Block chain [12].

\subsection{Expectation}

Victor Vroom argues in expectancy theory [13], that people will be motivated to do certain things to achieve their goals if they believe that their actions will lead to the achievement of those goals. This theory based on three main things: (1) Expectancy is an opportunity given that will occur due to behavior or an assessment that the likelihood of an effort will lead to the expected performance. (2) Value (Valence) is the result of specific behaviors having an 
individual value/dignity (power or value of motivation) for each individual concerned. Also, (3) Instrumentality is the perception of the individual that the results of the first level of expectation are something that exists within the individual that occurs because of the desire to achieve results following the goals/beliefs that performance will lead to rewards.

There are three main assumptions put forward by Vroom in the theory of expectations [14], namely: (1) Every individual believes that if he or she behaves in a certain way, he/she will get certain things. Sometimes what he or she does usually called outcome expectancy as a person's subjective assessment of the likelihood that a particular outcome will emerge from that person's actions. (2) Each result has a value or appeal to a particular person. Vale or valence as the value that people give to an expected outcome and (3) each outcome is related to a perception of how difficult it is to achieve results.

\subsection{Anxiety}

Anxiety is a state of negative mood with various physical signs or symptoms, such as physical tension and worries about the future. Anxiety can also afflict humans, namely in the form of subjective feelings about anxiety, some behaviors (looking worried, anxious or confused), or physiological responses that originate in the brain, which are reflected in increased heart rate and muscle tension [15].

Howard Liddell [15] proposes a concept of anxiety, as the "shadow of intelligence," which is the ability of humans to plan in detail for the future related to feelings of discomfort, and everything could be incorrect. Whereas Ivi Marie Blackburn \& Kate M. Davidson in her book [16], [17] classifying anxiety in functional analysis, namely: (1) Mood (anxiety, irritability, agitated feelings). (2) Thoughts (worry, difficulty concentrating, negative thoughts, exaggerate threats, view themselves as very sensitive, and feel helpless). (3) Motivation (avoiding situations, high dependency, and wanting to run away). (4) Behavior (restlessness, nervousness, excessive vigilance). (5) Biological symptoms (increased automatic movements, such as sweating, trembling, dizziness, palpitations, nausea, and dry mouth).

\section{Method}

The author retrieves data using the focus group discussion method and in-depth interviews. Participants selected from three different universities in Salatiga, Central Java, namely seven people from Satya Wacana Christian University, four people from the State Islamic Institute of Religion, and three people from the AMA College of Economics. The total number of participants as many as 14 people ( 8 female and six male) with an age range of 19-37 years (millennial generation). The participants were all college students. There are three small groups that we divide up based on their tertiary institutions. We explore data by conducting focus group discussions using open-ended questions. We proceed with in-depth interviews in order to collect specific data. The answers from these FGDs are not generic references, but the answers from each group may differ depending on the nature, understanding, characteristics, and expectations of the group.

\section{Result and Discussion}


In this study, we see that Society 5.0 arises from the development of Industry 4.0, wherein Industry 4.0, there are many technological changes, industrial digitalization, which is centered on computers and connected using the internet. For example, in the presence of an online taxi or GRAB, which is internet-based, everyone now becomes easier to order a taxi, no need to queue, and picked up wherever we stand. Various kinds of online businesses are mushrooming that do not need a place (tangible shop); you can even do in your home. Many young people (Millennial generations) are trying their luck by becoming video bloggers, with displaying excitement content, is an example of the impact of Industry 4.0.

We see through the lens of expectation and anxiety theory as follows: that the community or individuals who are ready with the impact of industry 4.0 we believe as a society or individuals who have expectations, who see the problem as a challenge [18]. On the other hand, people or individuals who are not ready for the impact of Industry 4.0 are people or individuals who are full of anxiety.

In the concept of Society 5.0, people or individuals who can survive/are ready are those who have an adaptive nature. Adaptive has the meaning of the ability of people to adapt quickly, change their behavior, especially technological changes, to meet the needs of a new market or environment [16], [17], [19], [20]. The community or individual will have the confidence to see the problem as a challenge (instrumentality), where the challenge will be realized with various efforts (effort). The effort is not just one kind or one time done, but adaptively, if deemed inappropriate, then they will be effortless to adapt and replace their efforts (performance).

The higher the challenge (instrumentality), the higher the effort also, expectancy, and performance that will be carried out by the individual. The adaptive effort, expectancy, performance, and great instrumentality will bring up valence (reward) [13], [21], [22] [16], [24], [25]. If related to expectation theory, then there are three main things in this theory, namely Expectancy, Valence, and Instrumentality. In the concept of expectancy, each individual believes that if he/she behaves in a certain way, he/she will get certain things. It is called an outcome expectancy as a person's subjective assessment of the likelihood that a particular outcome will emerge from that person's actions. In other words, adaptive society or individuals will have instrumentality, namely seeing the outcome of expectancy clearly like a challenge.

For example, there are a lot of CEOs or top managers in the world who are occupied by young people or the millennial generation, such as Mark Zuckerberg (34 years) -Facebook inventor; Dustin Moskovits (35 years)-inventor of Facebook, now own Asana; Adam D'Angelo (35 years) Co-founder and CEO of Quora; Nadiem Makarim (34 years) -inventor of Go-Jek-motorcycle (now Education Minister of Indonesia); Achmad Zaky (33 years) inventor of BukaLapak-Largest e-commerce platform in Indonesia; Ferry Unardi (31 years) founder and CEO of Traveloka). What we see today from CEOs or top managers around the world is the reward or valence they have gained. In order to do that, their minds embedded active instrumentality, where the problem or impact of industry 4.0 seen as a challenge. This challenge then realized by various adaptive efforts, which will affect to their performance. Society or individuals who succeed in terms of adaptation (adaptive) will bring excellent performance (performance) as well, and the result is a reward (valence).

Conversely, if the community or individual views something in the future as something scary, it will be prolonged stress; this stress will make anxiety/anxiety disorders. Liddell stated that, if the community or individual cannot plan in detail about the conditions in the future, then there will be feelings of discomfort, this uncomfortable feeling is the root of anxiety. An example is taxi transportation services, where in the past, taxis were a form of transportation 
that many people sought, even we were willing to wait in line to get a taxi. However, as industry 4.0 began to develop, many internet-based transportation services emerged (in Indonesia popular with GoJek and other countries such as America popular with GRAB), this condition made it easy to enter into society or individuals because everyone now uses gadget or smartphone and connected in a virtual environment. People began to abandon conventional taxis since there were GoJek and GRAB. Even in Indonesia transportation companies like BlueBird cannot stand alone; BlueBird collaborated with GOJEK and eventually became a form of Go-BlueBird application

Individuals like taxis drivers, if they cannot be adaptive to the surrounding environment (virtual environment, internet, operating gadgets, or smartphones), then the individual will feel stressed due to competition from online taxis (Go-Car, one of the products from Gojek or with GRAB). Which used to get a lot of customers or passengers; once there is a Go-Car or GRAB, the number of passengers will drop dramatically. This condition will trigger anxiety. If related to expectations theory, the taxi example is like individuals who do not have confidence or instrumentality; they will see the future of Industry 4.0 based on something scary or frightening. The impact of these feelings or beliefs will cause stress, and they will become passive because it is difficult or unfamiliar with gadgets or smartphones (not adaptive), even though their environment (virtual environment) or the surrounding community has used various applications in gadgets or smartphones. The condition will have an impact on their efforts (effort), and ultimately also have an impact on their performance. Our FGD results with millennial generation from three higher education/universities in Salatiga show some results that millennial generation has confidence (instrumentality) towards Society 5.0, and this belief makes millennial generation see Society 5.0 divided into two sides, namely expectations and anxiety. Expectations saw as something positive and anxiety as something negative.

\subsection{Positive and Negative about Society 5.0}

There are several positive sides about society 5.0, like Discipline humans, all autonomous/automatic, more practical, efficient and straightforward, more cost-effective no longer employ people but machines, more accurate and timely, humans become more respectful of time, humans will live more orderly, and cynical about Society 5.0

There are several adverse effects from Society 5.0, like Unemployment will rise because all things are machines; machines will replace human jobs; Humans are becoming more spoiled and more dependent on machines; Able or can weaken ourselves because the task/activities replaced by a machine; Becoming rarely move; There are no jobs for people whose roles are replaced by machines, then welfare/prosperity will threaten; Consumptive culture becomes high; Individualistic height; Our cultural roots will be eroded and lost; Decrease of social life so that the sense of need for others is increasingly absent; The condition of need each other will disappeared because there is someone who helps (AI / Robot); There will not be a mutual greeting between people but greet with machines; The interaction with humans decrease, but more interaction with machines; The population is decreasing because of its great individualistic, virtual relationship, and online sexual relationship; Crimes become high because unemployment rises; and Cyber-crime becomes high.

\subsection{Ideas or Strategies Towards Society 5.0}

Based on FGD, there are ideas or strategies to handle Society 5.0, like Maintain and uphold our native culture, reject foreign cultures that enter (e.g., Baduy tribe); Filtering or 
selective cultures that enter Indonesia, what we need to accommodate and adapt to our culture; Know more about Society 5.0; what are the advantages/disadvantages; We must be able to set the time when we have to use the technology (for example using an autonomous bus in particular date, or three days full using technology society 5.0) so that our dependence on the machine is not so high; Increase interaction with humans, reduce interaction with the media (smartphones); Self-discipline, know when to use a smartphone, work, or study; and Prepare mentally; not everyone relies on smartphones, some like direct interaction (smartphone agreements are collected in an event so they can interact with others).

There are three main points of Vroom's expectations theory, namely Expectancy, Valence, and Instrumentality. If it is related to the results of the FGD, millennial generations, have active instrumentality about the future, notably Society 5.0. This generation views that Society 5.0 with $\mathrm{Ai}$ and robots will make life more practical, simple, and many alternatives. Also, human beings themselves will become more disciplined, orderly and accurate. This positive or high instrumentality will also provide positive expectations, giving rise to various alternatives - their positive view of Society 5.0, which sees that these are challenges in the future. With various challenges and alternatives, the community or individuals will become adaptive and dynamic. Efforts can vary so that they can follow market needs, or even generate new alternative markets that have never existed before and produce maximum performance so that rewards (valence) they can get by effort, performance, and instrumentality.

Conversely, if instrumentality about Society 5.0 considers as a threat, then their point of view about society 5.0 will be negative. For example, unemployment will rise because machines will replace human jobs. Machines will begin to rule, and eventually humans will depend on machines. Because it is difficult to get a job, the welfare of their families will be threatened, while a higher consumerist culture. The individualistic side of a person is getting higher, and their origin culture begins to erode to make the social soul diminish. Because unemployment increases and work becomes difficult it will lead to crime and cybercrime. This negative instrumentality will give negative expectations as well, and this negative expectation will give rise to anxiety. Because of negative expectations and anxiety occurs, their efforts became non-adaptive, their performance diminished, and ultimately had an effect on reward that was not optimal.

\section{Conclusion}

From the explanation above, there are some conclusions: In Society 5.0, human or individual traits tend to be mechanical or mechanistic because everything is organized, accurate and completely autonomous (automatic). Anxiety will only occur or experienced by a group/people that are not ready with the presence of Society 5.0. People who can enter into Society 5.0 are people who can continuously adapt and dynamic to follow patterns of technology in Society 5.0. That human's or individuals' work not only influenced by the real environment around us but also influenced by the virtual environment. Everyone with the presence of Society 5.0 will undoubtedly feel anxious, but this anxiety does not need us to make a problem as long as we are ready. The key to the presence of Society 5.0 is adaptive and dynamic. Adaptive and dynamic society or individual will make efforts that effort will lead to many alternatives and the combination of alternatives, performance and instrumentality will give reward or valence 


\section{References}

[1] "Society 5.0: Japan's vision to live with robots | GovInsider." [Online]. Available: https:/govinsider.asia/connected-gov/society-5-0-inside-japans-vision-to-live-withrobots/. [Accessed: 31-Aug-2019].

[2] E. Prima, "Mengenal Visi Jepang Society 5.0: Integrasi Ruang Maya dan Fisik - Tekno Tempo.co." [Online]. Available: https://tekno.tempo.co/read/1170120/mengenal-visijepang-society-5-0-integrasi-ruang-maya-dan-fisik. [Accessed: 31-Aug-2019].

[3] M. Fukuyama, "Society 5.0: Aiming for a New Human-centered Society," Japan SPOTLIGHT, Vol. 27, No. 5, pp. 47-50, 2018.

[4] Y. Shiroishi, K. Uchiyama, and N. Suzuki, "Society 5.0: For Human Security and Well-Being," Computer, Vol. 51, No. 7, pp. 91-95, Jul. 2018. https://doi.org/10.1109/MC.2018.3011041

[5] S. B. Berkup, "Working With Generations X And Y In Generation Z Period: Management Of Different Generations In Business Life," Mediterr. J. Soc. Sci., Vol. 5, No. 19, pp. 218-229, 2014.

[6] U. S. Foerster-Metz, K. Marquardt, N. Golowko, A. Kompalla, and C. Hell, "Digital Transformation and its Implications on Organizational Behavior," J. EU Res. Bus., Vol. 2018.

[7] "Plattform Industrie 4.0 - Homepage." [Online]. Available: https://www.plattformi40.de/PI40/Navigation/EN/Home/home.html. [Accessed: 02-Nov-2019].

[8] T. Salimova, N. Guskova, I. Krakovskaya, and E. Sirota, "From industry 4.0 to Society 5.0: challenges for sustainable competitiveness of Russian industry," IOP Conf. Ser. Mater. Sci. Eng., Vol. 497, p. 012090, Apr. 2019.

[9] P. O. Skobelev and S. Y. Borovik, "ON THE WAY FROM INDUSTRY 4.0 TO INDUSTRY 5.0: FROM DIGITAL MANUFACTURING TO DIGITAL SOCIETY." https://stumejournals.com/ journals/i4/2017/6/307.full.pdf

[10] A. Savanevičienè, G. Statnickè, and S. Vaitkevičius, "Individual Innovativeness of Different Generations in the Context of the Forthcoming Society 5.0 in Lithuania," Eng. Econ., Vol. 30, No. 2, pp. 211-222, Apr. 2019.

[11] T. Cho, "Prepared for ICTA/CICC Joint Seminar," 2018. http://www.cicc.or.jp/japanese/kouenkai/pdf_ppt/pastfile/h29/180220-2Hitachi.pdf

[12] "Change is a Chance!" Retrieved https://www.meti.go.jp/english/publications/pdf/journal2016_09a.pdf

[13] F. C. Lunenburg, "Expectancy Theory of Motivation: Motivating by Altering Expectations,” 2011. https://www.nationalforum.com/Electronic Journal Volumes/Lunenburg, Fred C Expectancy Theory Altering Expectations IJMBA V15 N1 2011.pdf

[14] L.-E. Suciu, M. Mortan, and L. Lazăr, "VROOM'S EXPECTANCY THEORY. AN EMPIRICAL STUDY: CIVIL SERVANT'S PERFORMANCE APPRAISAL INFLUENCING EXPECTANCY," Transylvanian Rev. Adm. Sci., No 39, pp. 180-200, 2013.

[15] M. Durand, "Abnormal psychology: An integrative approach (6th ed.)." https://www.academia.edu/ 26181562/Abnormal psychology An integrative approach 6th ed.

[16] J. L. Huang, A. M. Ryan, K. L. Zabel, and A. Palmer, "Personality and Adaptive Performance at Work: A Meta-Analytic Investigation," 2013. https://doi.org/10.1037/a0034285 
[17] D. K. Jundt, M. K. Shoss, $\uparrow$ And, and J. L. Huang, "Individual adaptive performance in organizations: A review," 2014. https://doi.org/10.1002/job.1955

[18] M. E. Gladden, "Who Will Be the Members of Society 5.0? Towards an Anthropology of Technologically Posthumanized Future Societies," Soc. Sci., Vol. 8, No. 5, pp. 1-39, 2019.

[19] A. Charbonnier-Voirin and P. Roussel, "Adaptive Performance: A New Scale to Measure Individual Performance in Organizations," Can. J. Adm. Sci. / Rev. Can. des Sci. l'Administration, vol. 29, no. 3, pp. 280-293, Sep. 2012. https://doi.org/10.1002/cjas.232

[20] C. K. Stokes, T. R. Schneider, and J. B. Lyons, "Adaptive performance: a criterion problem,” Team Perform. Manag. An Int. J., Vol. 16, No. 3/4, pp. 212-230, Jun. 2010.

[21] K. T. Boulanger, "Factors related to satisfaction, pain and affect outcomes in massage therapy clients.," Diss. Abstr. Int. Sect. B Sci. Eng., Vol. 76, No. 11-B(E), 2016.

[22] S. Furlich, "Understanding employee motivation through managerial communication using Expectancy-Valence Theory," J. Integr. Socal Sci., Vol. 6, No. 1, pp. 17-37, 2016. 